\title{
3D MODELLING: CROSSING TRADITIONAL BOUNDARIES BETWEEN DIFFERENT RESEARCH AREAS
}

\author{
L. Opgenhaffen ${ }^{a}{ }^{*}$, M.H. Sepers ${ }^{\text {a }}$ \\ a 4D Research Lab, ACASA, University of Amsterdam, The Netherlands - (l.opgenhaffen, m.h.sepers)@uva.nl
}

Commission V, WG V/4

KEY WORDS: Interdisciplinarity, 3D modelling, architecture, GIS, dialectic model, common integrative approach

\begin{abstract}
:
A 3D reconstruction of complex architecture will never be complete nor constructively sound without the combination of knowledge and expertise from different scientific branches. Yet, how should all the different perspectives from these diverse disciplines, leading to different ideas and views on material, be approached, in order to convert the knowledge to a coherent model? It is the goal of this paper to contribute to the development of a common approach to diverse datasets, ideas and interpretations that are involved in the creation of 3D reconstructions. The outline of our suggested approach is demonstrated though two case-studies differing in time and region, but revolving around the same research topics, showing that the approach is universally employable. Therefore, interdisciplinarity - one of the key principles of the Seville Charter - will be the leitmotif of this paper.
\end{abstract}

\section{INTRODUCTION}

Reconstructions, be it drawings, descriptions or video's, visualize thoughts and experiences, manage complex data and guide the interpretative process. They are a powerful tool to communicate this otherwise abstract process through images to the outside, material world. The most innovative research tool of today, 3D technology, enable that scientists from different research areas can collaborate and transcend and expand their knowledge through the connection of data, thoughts and ideas in a 3D model. Being enriched with all available data, the 3D models are elevated to dialectic ontologies, creating virtual environments to test and analyse the social dynamics of ancient built environments.

Yet 3D models do not convey the information themselves. It is the process towards the $3 \mathrm{D}$ model that does. It is the gathering of data and research to build the model and the choices that where made by the modellers and/or scholars (i.e. their agency) that conveys the information that leads to an interpretation (Earl 2012; Forte 2008; Hermon 2008). These interpretations can now be more comprehensive than ever because the extra dimension forces to look for anwers, and frequently these answers are outside the research area and even the field of the specialist. Therefore a 3D reconstruction may be regarded as the status-quo of what is known about a specific subject, from the excavated site to the role of the associated material culture with its social implications. It is not the $3 \mathrm{D}$ reconstruction of ancient architecture that proves something by itself, but it is how we engage with the model in order to unravel how someone in the past might have engaged with it .

Therefore we cannot stress enough that - and we are certainly not the first - that 3D modelling is primarly a research tool. We stress that $3 \mathrm{D}$ techniques are most valuable if used as a method to enhance and enrich any ongoing research. It is a transdisciplinary tool that requires to comprise knowledge from all disciplines: it compels specialists to move beyond their specialization and cross their traditional boundaries of research areas.

\section{TWO CASE-STUDIES}

\subsection{Introduction}

Through the description of the workflow of two case-studies we try to explain how we collaborate with other disciplines and how we treat the data obtained from these collaborations. The first case describes the pursuit to a famous historical figure who lived in a 'prominent' house in early $16^{\text {th }}$ century Amsterdam. The second case concerns a cluster of houses from the Archaic period of the Etruscan town Acquarossa, Italy.

\subsection{The house of Pompeius Occo)}

Dr. Madelon Simons, art historian at the University of Amsterdam, does research to the historical figure named Pompeius Occo. Occo was German-Dutch banker who came in 1510 to Amsterdam to establish a branch of the Fugger bankers. He was one of the richest person of the town in his days and a respected mecenas for the arts. Dr. Simons had a collected a lot of historical data and descriptions of Occo and his house and uncovered a local network of the mecenas, artists and other dignitaries. Even the exact adress of Occo's house, called ' $t$ Paradijs, was found in the city archives: Kalverstraat no. 13 and the adjacent house, Rokin no. 6. These houses do not exist anymore, but on the oldest city-map of Amsterdam, dated to 1544 , the houses could be identified, which gave an impression of the features of the houses. Art historians working on Occo's life previous dr. Simons, thought it was the prominent house on the map, the house with the façade with the curlicues. The map was interpreted as it fitted the predetermined ideas of the art historians, and consequently the alley at which the prominent house was located, must have had an angle, which made it the only alley in the city with an angle. Dr. Simons uncovered from literature-, art-, and archival studies much details about specific

\footnotetext{
* Corresponding author. This is useful to know for communication with the appropriate person in cases with more than one author.
} 

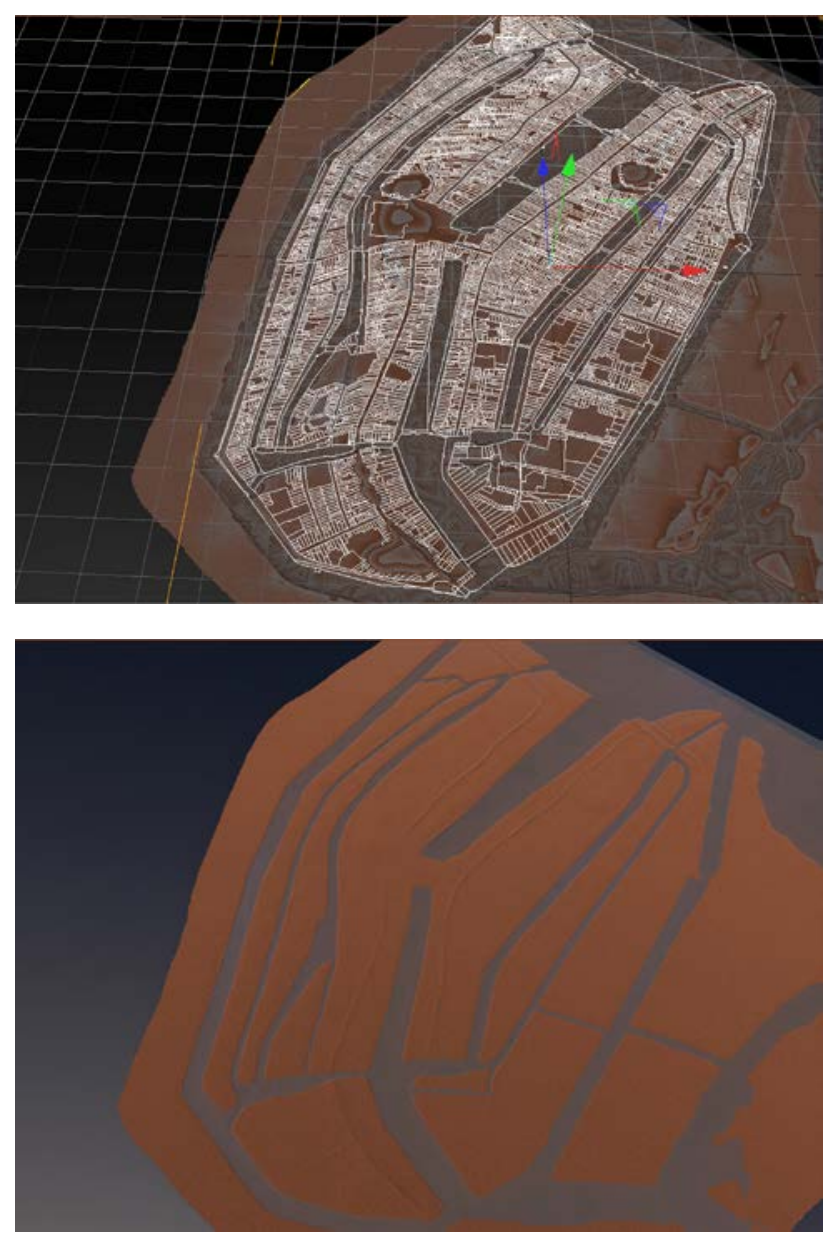

Figure 1. The GIS map imported in Cinema4D and landscape reconstructed (images by L. Opgenhaffen)

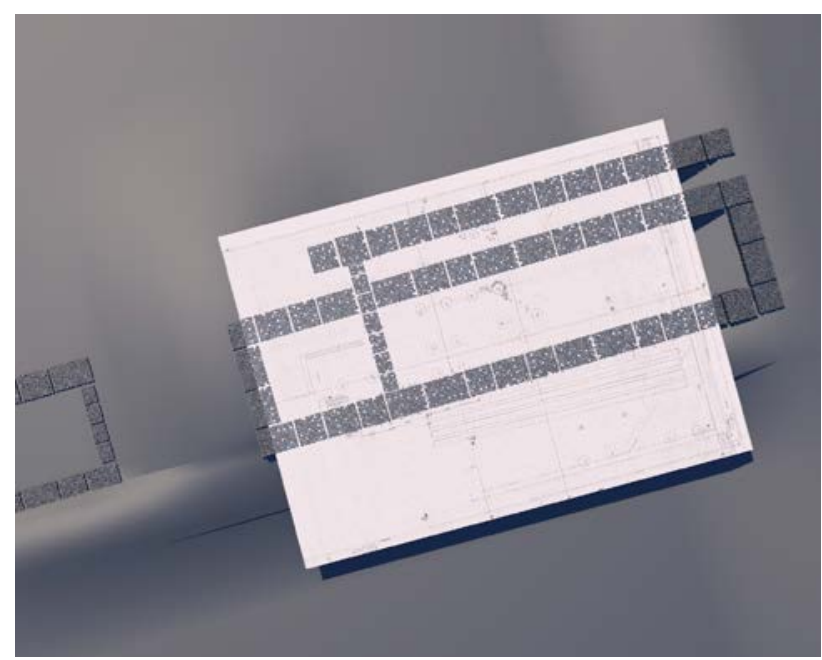

Figure 2. Excavation drawings are imported and build upon (image by L. Opgenhaffen) spaces in the house, such as a comptoir, a library, pieces of art, and a reception hall. But, she also assumed, houses at that time could only have been of modest size: 5 x 6 meters. How then did this erudite person received the Danish king with its entourage and 40 Dutch maidens? Where did these people danced and watched the joust on the canal? Therefore the houses along the alley had to be reconstructed in order to simulate the movement of all these people and how Occo must have lived.

To reach this dr. Simons had to trancend her traditional academic boundaries and visited the 4D Research Lab at the archaeological department (ACASA). At the 4D Lab the archaeologist/modeller asked for actual data, which was a huge surprise for the art historian, who only had art historical descriptions and assumptions. An transdisciplinary project was born, that rapidly expanded to include building historians, the public archaeological service of the city (BMA) and an historical GIS service that provided the digitized map of the oldest register-map of Amsterdam from 1832 (HISGIS).

The GIS map provided the starting point for the reconstruction of at least the area around the houses of Occo, and was imported in the 3D modelling program Cinema4D. First, the GIS map was used in combination with the Dutch national height map (AHN) to reconstruct the landscape with the dykes and canals. This needed additional research to the changing landscape with support from from the city's archaeological service to reconstruct drained canals and ditches. After that, we started with a basic test of placing simple houses in the parcels. That proved directly that the alley was straight and could never have had an angle. This was further confirmed by inserting the archaeological drawings (from the early 1980's, that were now for the first time actually studied, digitized and geo-referenced) into and onto the model, providing the evidence that there was never an angle in the alley and the house of Occo could not have been the 'prominent' house with the curlicues. The house of Occo was on the other side of the alley, perfectly corresponding to the adjacent house at the back of which was known that Occo bought that too. 'Prominent' was therefore in the early sixteenth century understood differently than we perceive it today.

From this point onwards we could start modelling 'for real', from the foundations onwards that were recorded on the archaeological map (which also proved, among a lot of other indications, that the house was not only $5 \times 6 \mathrm{~m}$, but $8 \times 18 \mathrm{~m}$ ), and test if these art historical descriptions could literally stand on the foundations, which were, of course, reconstructed first. Immediately another problem occurred when the foundation was laid and the wooden timer frame had to be built on it; how were early sixteenth secular buildings actually constructed? Additional information had to be sought with building historians. The additional research to complement the integrity of the reconstruction of the house of Occo, consisted, for example, of research to timber frame construction, types of late medieval foundation techniques, dendrochronologic analysis, brick building, research to parallells of existing late medieval buildings, fire places and chimneys, windows and doors, and so forth.

When the construction was finished the interior could be reconstructed according to and limited by the construction of the building, preventing random placement of quarters. It is not in the scope of this article to go into further detail, as the main 


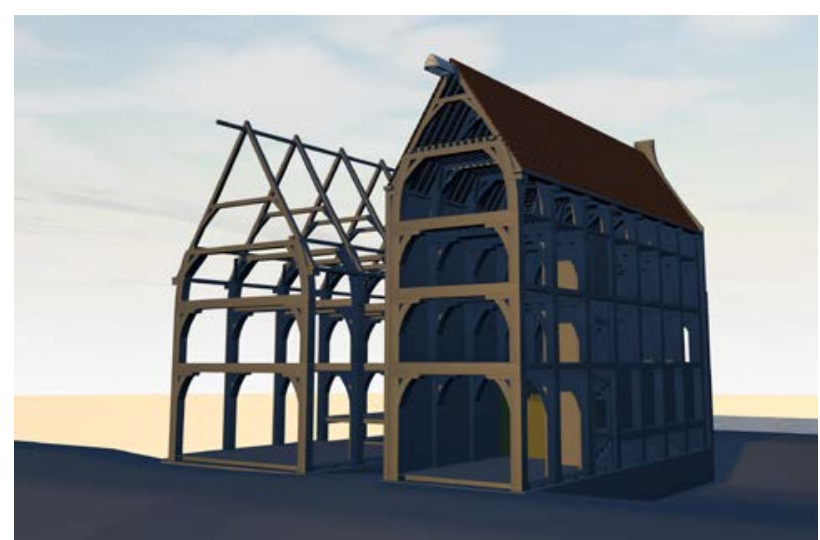

Figure 3. Reconstruction of the timber frame (image by L. Opgenhaffen)

goal is to demonstrate the potential of interdisciplinary research and 3D modelling as a coercive reseach tool.

Finally, the computational specialist of the 4D Research Lab developed a database which is able to show 3D models connected with the data and metadata on which the reconstruction is based on. It is possible to rotate and pan the model in the database and click on a random part, which subsequently shows what data is connected with this part of the model, making the model highly transparent and interactive.

\subsection{Houses from Acquarossa}

The second case-study concerns the reconstruction of a part of the settlement area ("zona B") of Acquarossa. This Etruscan town Acquarossa, near modern Viterbo, Italy, was situated on a tufa plateau, and arose in the Orientalizing period and remained in use until its abandonment in the second half of the $6^{\text {th }}$ century B.C. Several excavation campaigns were undertaken in the late 1960s and 1970s by the Swedish institute at Rome. The excavations yielded a very rich archeological site with clusters of buildings (divided in so-called zone) associated with the transitional period from 'huts to houses': the urbanisation process in the Italic peninsula $\left(8^{\text {th }}-6^{\text {th }}\right.$ century B.C.). After the site was abandoned 2500 years ago, the land was mostly used for agricultural purposes thence providing an unique opportunity to study the development an Etruscan settlement.

This general outline of the excavation history of Aqcuarossa indicate that a huge amount of (archaeological) data was uncovered during the excavations resulting in a wide variety of interpretations about the architectural situation in the past. In this case-study special attention is devoted to the area known as 'zona B'. In this area remains of a cluster of buildings was found and attributed to at least two, perhaps even three phases. The buildings were largely constructed from perishable materials such as wood and adobe and have been subject to a variety of post-depositional processes, like the possible re-use of building materials, erosion and most prominent, modern farming activities. These processes ultimately resulted (at least partially) in obscuring the material remains from this period. Notwithstanding these difficult circumstances of the remains, exhaustive research has been carried out to the material culture of Acquarossa that was subsequently published in several journals and books and even resulted in (permanent) museum exhibitions. The interpretation of the architectural remains of

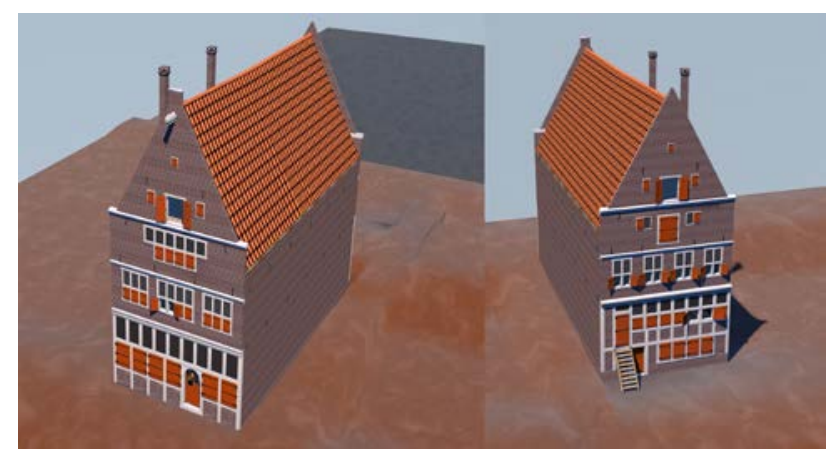

Figure 4. The house of Pompeius Occo, 't Paradijs. Left: front side. Right: back side (image by L. Opgenhaffen)

the buildings, and even more so ascribing the remains to different building phases, is not as simple as it may appear. The main enquiry is therefore to how this cluster of houses were constructed in the Archiac period. 3D modelling is applied as a research tool to explore ancient building practices in this particular site. Engineers from the building company Grontmij will check and if necessary revise the constructional part of the recontruction of the houses.

Many reconstructions of the vernacular architecture have been suggested. These reconstructions, however, are still preliminary in the sense that they should be regarded as an illustration of the (temporal) interpretation of how the area might have looked like. The final report on the excavations in 'zona B' is not published yet. But from the research of a specific find categories, the roofing systems proved to be very valuable for reconstructions of the exteriors of the buildings of 'zona B'. The research included recognizing deposition patterns and trying to understand ancient roofing techniques. Based on other, novel insights, earlier visualisations proved to be implausible or even wrong, and with the 'new' data, derived from the research on roofing materials, other reconstructions could be suggested. All known theories and interpretations of this cluster of houses of Acquarossa will be tested in the virtual environment. In the final 3D model, these different hypotheses are visualised as variations of the same model. Alterations and adaptations can be visualised through layers, leaving the actual remains and other data intact and accessible.

The analogue data of the landscape was first digitised in qGIS and subsequently the architectural remains could be georeferenced to this model. The GIS model serves as an intermediary between the 3D reconstruction and the database in which all the collected data is stored. The model of the landscape was then exported to the 3D modelling program Cinema4D for further elaboration and to actual test the constructional methods of the superstructure and roofing system of the houses.

\section{CONCLUSION}

On the basis of the two case-studies we propose a distinct integrative approach by using - among other digital tools - 3D modelling as a research tool in the interpretative process. For the first time are excavation, geological and (art) historical data, previous analogue research and interpretations on material culture, ideas on construction, ideas concerning visual aspects, knowledge about available resources, combined through digital techniques. These digital techniques include the application of data management systems, GIS and 3D modelling, that make it 


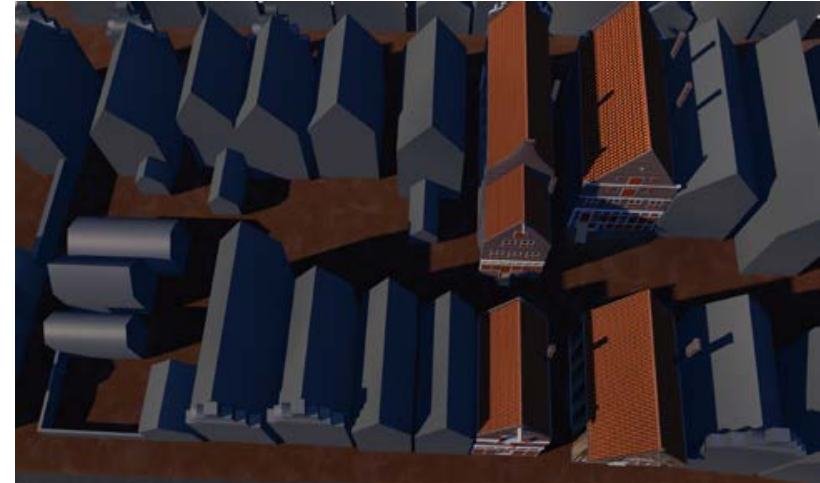

Figure 5. Reconstruction of the alley (image L. Opgenhaffen)

possible to create a visualisation of the current state of knowledge and ideas towards this Etruscan settlement and a late medieval house in Amsterdam. In doing so, through the placement of data in a framework of (visible) relations, a variety of questions occur and choices have to be made. These questions and choices produce unforeseen emerging properties of materials and draw attention to problems in data quality and consistency, frequently leading to many different options, constraining the researcher to continuously reconsider, reassess, and most important, demonstrate these choices. As a result large datasets are created that can be directly connected with the visual output. This visualization might be considered as a rendering of our interpretation of the ancient material culture and not as a mere reflective historiographic representation. The availability of the dataset behind the visualization can assist the critical reviewer of the model to determine its validity, add or review data, add interpretations, and ultimately revise the model.

In this light, we developed the concept of a 'dialectic 3D model'. Archaeologists move between information, argumentation, evidence, hypothesis and interpretation, which are moving simultaniously on itself too (after Gooding 2008). This is no lineair progressive path: it moves between the interpretation of new data (added to the database and thence processed into the $3 \mathrm{D}$ model), through new hypotheses that give meaning to to this new data (these new hypotheses can be tested in the $3 \mathrm{D}$ model/environment), to arguments that may be transformed into evidence for an explanation, the 'final', albeit temporal, 3D model. Moreover, the possibility to move between different dimensions, structures the explanation (Gooding 2008, 17): the 3D models structures the archaeological interpretative process. The dialectic 3D model is always subject to change (to put it in Hegelian terms) and therefore never 'finished', making it an ultimate goal to improve our knowledge of past built environments.

Through these case-studies we try to explain how 3D modelling and interdisciplinary collaborations can be deployed as a common integrative approach to enhance and enrich ongoing research, and let it play an active role in not only the archaeological discours, but the humanities as a whole.

\section{ACKNOWLEDGEMENTS}

First and foremost we wish thank dr. Patricia S. Lulof, who founded the 4D Research Lab, and inspired us contribute to the development of a methodology for 3D modelling as a research tool. Further we like to express our gratitude to the research

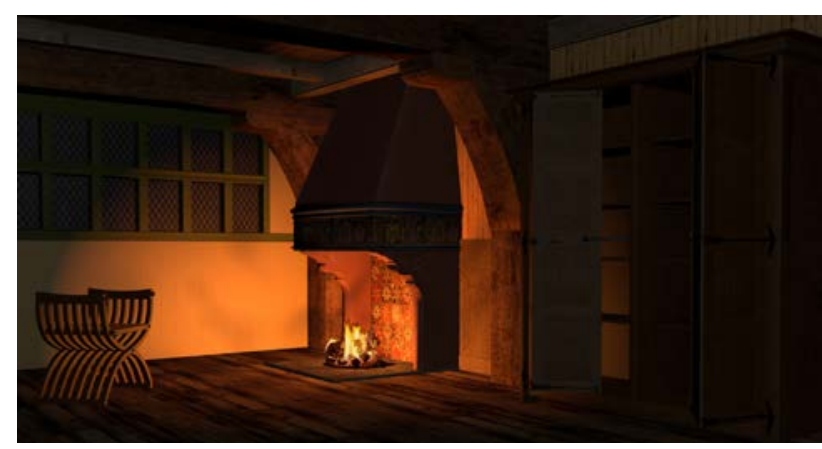

Figure 6. Reconstruction of the interior of the house of Occo (image L. Opgenhaffen)

project 'CREATE: an e-humanities perspective', headed by prof. dr. Julia Noordegraaf, who financed the reconstruction of the house of Occo. We also are very grateful to Lara and Rafaele Rocchi, who assisted in the onsite exploration of Acquarossa, dr. Madelon Simons for initiating the reconstruction-project of the house of Occo, Jerzy Gawronski, Jorgen Veerkamp and Dick de Roon from BMA, and, finally the engineers of Grontmij. Without you our buildings could not have withstand.

\section{REFERENCES}

Earl, G., 2013. Modelling in Archaeology: Computer Graphic and other Digital Pasts. Perspectives on Science, 21 (2), pp. 226-244.

Forte, M., 2008. Virtual archaeology: communication in 3D and ecological thinking. In: Frischer, B. \& Dakouri-Hild, A. eds. Beyond Illustration: 2D and 3D Digital Technologies as Tools for Discovery in Archaeology, Oxford, Archaeopress (BAR International Series 1805), pp. 20-34.

Gooding, D.C., 2008. Envisoning explanation: the art in science. In: Frischer, B. \& Dakouri-Hild, A. eds. Beyond Illustration: $2 D$ and $3 D$ Digital Technologies as Tools for Discovery in Archaeology, Oxford, Archaeopress (BAR International Series 1805), pp. 1-19.

Huggett, J., 2012. What Lies Beneath: Lifting the Lid on Archaeological Computing. In: Chrysanthi, A. \& Murrieta Flores, P. \& Papadopoulos, C. eds. Thinking beyond the Tool. Archaeological computing and the interpretive process. Oxford, Archaeopress (BAR International Series 2344), pp. 204-214.

Huvila, I., 2012. The Unbearable Complexity of Documenting Intellectual Processes: Paradata and Virtual Cultural Heritage Visualisation. Human IT, 12 (1), pp. 97-110.

Lulof, P.S., 2011. The Art of Reconstruction. De wetenschappelijke waarde van 3D-simulaties bij de analyse van pre-Romeinse tempels en daken. TMA, 46, pp. 14-24.

Ryan, N., 2001. Documenting and validation virtual archaeology. Archeologia e Calcolatori, 12, pp. 254-273. 